\title{
LETTERS
}

\section{Response to: "Beyond implementation research for improving maternal, newborn and child health globally"}

We thank Dr. MacDonald and colleagues for their letter. ${ }^{1}$

Notwithstanding our admiration of their initiatives to support grass root research capacity enhancement in low- and middleincome countries, we believe that their critique of our implementation research prioritization exercise is misplaced.

In our commentary and article, ${ }^{2,3}$ we undertook to advocate for high-quality implementation research to address priority gaps, but at no stage did we suggest that this be a "top-down" process imposed by groups in Canada or elsewhere. In fact, we do hope that, as funding for implementation research increases, there will be huge opportunities for proactively engaging implementation groups and researchers who are based in low- and middleincome countries.

The point of an exercise similar to the approach taken for child health and nutrition research initiatives is not to establish a research agenda for every local context, but to systematically identify the broader research gaps in the global health literature/ discourse that could maximize impact/ equity in various settings. These priorities could be general guidance on assessing and developing research priorities, but they should be operationalized in the local context, in close coordination with local experts.
At the moment, resources for implementation research are extremely limited, and we advocated for enhancing and adequately financing Canada's investments in high-quality implementation research, and prioritizing areas that need the greatest attention. Some of these could include small grants and capacity enhancement for implementation research through initiatives such as MicroResearch.

\section{Zulfiqar A. Bhutta MBBS PhD}

Co-Director, Centre for Global Child Health, The Hospital for Sick Children, Toronto, Ont.

\section{Renee Sharma MSc}

Research assistant, Centre for Global Child Health, The Hospital for Sick

Children, Toronto, Ont.

Cite as: CMAJ 2017 May 23;189:E730. doi: $10.1503 / \mathrm{cmaj} .733048$

\section{References}

1. MacDonald NE, Bortolussi R, Kabakyenga, J et al. Beyond implementation research for improving maternal, newborn and child health globally [letter]. CMAJ 2017;189:E729.

2. Sharma R, Scott H, Bhutta ZA. Enhancing implementation research within Canada's investments in the health of women and children globally. CMAJ 2017;189:E332-3.

3. Sharma R, Buccioni M, Gaffey MF, et al.; Canadian Expert Group on Maternal, Newborn, Child and Adolescent Health. Setting an implementation research agenda for Canadian investments in global maternal, newborn, child and adolescent health: a research prioritization exercise. CMAJ Open 2017;5:E82-9.

Competing interests: None declared. 